\title{
Early Newborn Bath Practice and Its Associated Factors in Jimma, South West Ethiopia, 202I
}

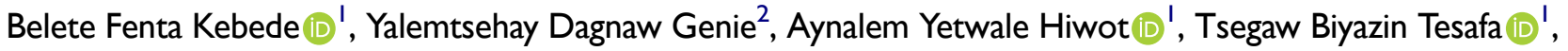 \\ Betelhem Abebe' \\ 'School of Midwifery, Institute of Health, Jimma University, Jimma, Ethiopia; ${ }^{2}$ Department of Nursing, Mizan-Tepi University, Mizan-Teferi, Ethiopia \\ Correspondence: Yalemtsehay Dagnaw Genie, Department of nursing, Mizan-Tepi University, 260, Mizan-Teferi, Ethiopia, Tel +25193287474I, \\ Email tsehayworld@gmail.com
}

\begin{abstract}
Aims: The timing of the first bath is an important variable in newborn care despite variations from setting to setting. Early first bath can affect the newborn's temperature, blood sugar levels, bonding with his/her mother, comfort, and security. Thus, timing affects several aspects of newborn care and is still a major concern. However, in Ethiopia, there is insufficient evidence regarding newborn bath timing. Therefore, this study aimed to assess early newborn bath practice and its associated factors in Jimma, Southwest Ethiopia, 2021.

Materials and Methods: An institutional-based cross-sectional study was conducted from July to August 2021 on 388 postpartum women who came for newborn immunization. Data were collected through face-to-face interviews using a structured questionnaire. Data were entered into Epi-data 4.4.2.1 and exported to Stata version 14 for cleaning and analysis. Logistic regression was used to determine the association between explanatory and response variables. The level of significance was declared at a $p$-value of less than 0.05 in multivariable logistic regression.

Results: This study revealed $126(32.5 \%)$ of mothers were practicing early newborn bathing. Vaginal mode of delivery (AOR: 3.84 (95\% CI: 1.96-7.52)), poor knowledge about danger signs (AOR: 6.78 (95\% CI: 3.77-12.19), poor knowledge about hypothermia (AOR: 0.35 (95\% CI: 0.20-0.58) and educational level of women (AOR: 0.33 (95\% CI: 0.15-0.73) were variables significantly associated with early newborn bathing practice.

Conclusion: Early neonatal bathing practice in this study is high and needs priority as it results in neonatal hypothermia and its complications. Therefore, Education for women and their families on delayed bathing of their newborns could begin in antenatal care visit, on admission into the labor and delivery unit and again on the postpartum unit.
\end{abstract}

Keywords: early newborn bath, the timing of newborn bath, associated factors, Ethiopia

\section{Introduction}

Newborns are unable to regulate and maintain their body temperature without thermal care, protection and bathing are significant factors affecting thermoregulation in newborns. ${ }^{1}$ Bathing is a regular occurrence for all newborn infants but bathing practices and skincare have traditionally been based on culture, regional customs, and anecdotal experiences. ${ }^{2}$ The World Health Organization (WHO) recommends delaying the bath for $24 \mathrm{hrs}$, or if this is not possible due to cultural reasons, waiting at least 6 hrs., to prevent hypothermia. ${ }^{3}$ Many studies have affirmed that the first bath should be given only once the infant has achieved cardio respiratory/ vital signs and thermal stability. ${ }^{5,14}$

Cleansing/bathing the neonate should be delayed until their temperature is stable above $36.50 \mathrm{C}$ usually after the first $24 \mathrm{hrs}$, unless there is a risk of infection (eg maternal HBV or HIV positive) from the mother. ${ }^{4}$ The Effects of bathing on newborn temperatures vary depending on the newborn's condition, type of bath, and timing. ${ }^{6}$ Effective self-regulation of body temperature can be a tremendous challenge for a newborn's competence in temperature regulation and bathing too early can lead to increased oxygen requirements and hypoglycemia. ${ }^{7}$ Evidence from previous literature indicating that delaying of the first bathing time of newborns was effective in preserving body temperature and seems to have a positive impact on the infant's temperature regulation, glucose stability, promotes successful initiation of breastfeeding, facilitates bonding and skin-to-skin care. ${ }^{8-10}$ 
First newborn bathing contributes to hypothermia and leads to negative consequences of mortality which was $15.4 \%$ with hypothermia in low resource settings. ${ }^{11}$

Findings from study conducted in India, support the idea that delayed bathing is beneficial practice to prevent infection. ${ }^{12}$ In Lebanon, higher percentages (65.2\% and 33.3\%) of newborns who had skin-to-skin contact with their mothers had their bath after birth at 24 vs 2 hours respectively. ${ }^{13}$ The prevalence of neonatal hypothermia on admission to the neonatal intensive care units in Southwest Ethiopia was $50.3 \%$ as early newborn bathing was a highly associated indicator for this complication of the newborn. ${ }^{14}$ Even though education on newborn care, neonatal danger signs and bathing time for new-born's are parts of routine education of every mother after delivery in Ethiopia, knowledge gap about first bathing and hygiene practices among postnatal mothers leads to early newborn bathing. ${ }^{15}$ Knowing the correct first bathing time was significantly associated with good newborn care practices of mothers. ${ }^{16}$ In Eastern Ethiopia, around $12.5 \%$ of women reported that time of the first bath should be before $24 \mathrm{hrs}$ and $3 \%$ of mothers were do not know the first time of bath. ${ }^{17}$ Mostly mothers with primi Para status, mothers who had no knowledge of hypothermia and uneducated mother were practiced early newborn bathing. ${ }^{18}$ Although the first newborn bath is routine and contributes to hypothermia, researchers have paid little attention to supporting the current practices in Ethiopia. Therefore, this study aimed to assess early newborn bath practice and associated factors among postpartum women who gave birth in the last six months in Jimma town/ Southwest Ethiopia.

\section{Materials and Methods}

\section{Study Design, Area, and Period}

This cross-sectional study was conducted at Jimma town public health institutions from July to August 2021. The town is located in the Jimma zone, in the southwestern part of Ethiopia, and is approximately $352 \mathrm{~km}$ away from Addis Ababa, the capital city of Ethiopia. The town has five public health centers and two public hospitals (one referral and one district). The referral hospital is Jimma Medical Center (JMC) is one of the oldest public hospitals in the country it was established in 1937 by Italian invaders. The hospital provides service to 15-20 million residing in Oromia, Gambella, Southern nation nationalities and Peoples Region (SNNPR) and Benishangul regions even for neighboring south Sudan with 1800 staff members including 550 nurses with 32 intensive care units and 800 beds. It provides many services under many departments, such as the pediatric ward, medical ward, surgical ward, maternity ward, obstetrics, gynecology ward, maternal and child health ward, operating room, emergency outpatient department, delivery room, psychiatric clinic, dental and eye clinics, laboratory service, ultrasound and other imaging studies. Shanan Gibe Hospital is one of the district hospitals in Jimma town, which provides many services under departments such as medical, pediatric surgical, maternity, obstetrics and gynecology, maternal and child health, operating room, and emergency outpatient department. According to the 2007 census of Ethiopia, the total population of Jimma is 182942 of these 91,771 are males and 91,171 are females. The main languages spoken in the town are Afan Oromo and Amharic.

\section{Population}

All postpartum women who gave birth in the last six-month and come for newborn immunization to Jimma town public hospitals were the source population whereas all sampled postpartum women who gave birth in the last six-month and come for immunization to Jimma town public hospitals during the data collection period were considered as the study population.

\section{Eligibility Criteria}

Women who came for immunization and were present in the hospital during the data collection period were included while, mothers who brought their newborn without the involvement of the first bath/not knowing the status of the first timing of bathing for newborns and mothers unable to speak and hear were excluded.

\section{Sample Size Determination}

The sample size was determined by using a single population proportion formula considering the following assumptions; $95 \%$ confidence level, margin of error (0.05) and proportion of early newborn baths from previous study (35.4\%). ${ }^{18}$ 


$$
\begin{aligned}
& \mathrm{n}=(\mathrm{Z} \alpha / 2)^{2} \times \mathrm{p}(1-\mathrm{p}) /(\mathrm{d})^{2} \\
& \mathrm{n}=(1.96)^{2} * 0.354 * 0.646 /(0.05)^{2}=352 .
\end{aligned}
$$

The sample size after adding a $10 \%$ non-response rate was 388 .

\section{Sampling Technique and Procedure}

The average number of clients who were followed for immunization at each facility in the month preceding the data collection period which was approximately 557 from both hospitals (A total of 314 and 243) neonatal immunizations were obtained over one month preceding the data collection period from JUMC and Shenen Gibie Hospital respectively. The samples were proportionally allocated to each hospital (219 from JUMC and 169 from SGH). A systematic sampling method was used to select study participants who attended newborn immunization during the data collection period. Participants' card number were used to systematically select study participants at every $\mathrm{K}$ interval taking $\mathrm{K}=\mathrm{N} / \mathrm{n}=557 /$ 388 ) $=$ two (where $\mathrm{N}$ is the source population and $\mathrm{n}$ is the sample size for this study).

\section{Variables of the Study}

The dependent variable was "Timing of newborn first bath" dichotomized as early and late newborn bath timing.

The independent variables of the study included: Socio-demographic characteristics; (Sex of neonate, maternal age in years, ethnicity, religion, marital status, educational status, maternal residency, Maternal Occupation). Obstetric-related characteristics: (gravidity, parity, place of delivery, type of pregnancy, Preparedness for delivery, Complications during recent pregnancy, previous chronic medical problem, presentation, mode of delivery). Health facility-related characteristics: (KMC, NICU admission history, postnatal care follow up during last birth, ANC during last pregnancy). Women's knowledge: knowledge (type of water used for newborn bathing, Bathing techniques, Neonatal danger signs and hypothermia).

\section{Operational Definitions}

\section{Early Bathing}

The immersion of all or part of the body of a newborn in water or some other liquids for cleansing or refreshment before 24hrs after delivery.

\section{Late Bathing}

Delaying the baby's first bath until 24 hrs. After birth. ${ }^{3}$

\section{Data Collection Tools and Procedures}

Data were collected using a structured and pretested questionnaire through face-to-face interviews at mothers 'exit time (after study participants received the immunization service) which was adopted after reviewing several types of literature. ${ }^{18}$ All information was retrieved from mothers who came for immunization during the data collection period.

The tool was first prepared in English and then translated into local languages (Afan Oromo and Amharic)) and retranslated back to English to check its consistency. Women's socio-demographic, Obstetric related characteristics, Health facility-related characteristics, Women's knowledge about newborn bathing technique and Hypothermia. Two BSc midwives were collecting the data and they were trained for one day about the objective of the study before they go-to data collection. One MSc nurse was assigned as a supervisor in each hospital.

\section{Data Quality Control}

In order to ensure quality of data, pretest was done on $5 \%$ of the sample size of the study one week priors to the actual data collection period from other health facility on women those were not included in the actual study. Based on the pretest result wording, language consistency and edition made. Principal investigator and supervisor were checking daily the completeness of the filled tool. 


\section{Data Processing, Analysis, and Presentation}

After checking data completeness and consistency, the collected data were coded and entered into Epi-data version 4.4.2.1 (www.epidata.dk/download.php), exported into Stata version 14 (www.stata.com) for cleaning and analysis. The statistical analyses performed to all collected maternal, obstetrics, health facility and neonatal characteristics. Chi-square tests were used to test the differences between the early and late neonatal bathing data for independent variables. The ordinary logistic regression model was used to identify the independent factors associated with early neonatal bathing. Bivariate and multivariable logistic regression analyses were done to determine the association between predictor variables and the dependent variable.

The variables were checked for multicollinearity and normality, using a higher variance inflation factor (VIF) and statistically significant correlations. Based on bivariate analysis, those variables having p-value $<0.25$ in the bi-variate analysis were transferred to the multivariable analysis. Adjusted odd ratios (AOR) with $95 \%$ confidence interval (CI) were computed, and variables having P-value less than 0.05 in the multivariate logistic regression model were considered as statistically significant with early neonatal bathing. Descriptive statistics like frequency tables, cross-tabulations, and pie chart were used to present the result findings.

\section{Results}

\section{Women's Socio-Demographic Characteristics}

In this study, a total of 388-study participants were interviewed, making a response rate of $100 \%$. About $335(86.3 \%)$ of the mothers were in the age group of 20-34 years. The majority $366(94.3 \%)$ of mothers were married and $374(96.4 \%)$ of them were lived in urban. Regarding religion, the majority of mothers 185 (47.7\%) were Muslim and ninety-four (24.2\%) of respondents had completed their primary School education (Table 1).

\section{Obstetric Related Characteristics}

The majority 374 (96.4\%) of the mothers were given birth at a health facility. Three hundred sixty-seven (94.59\%) of mothers had singleton pregnancy. Of the respondents, 211 (54.38\%) of them were had a parity of two and more. About $352(90.7 \%)$ of mothers had birth preparedness before the recent delivery and $332(85.6 \%)$ of mothers had postnatal care in recent baby births. Only $13(3.4 \%)$ of mothers had a chronic medical illness. The majority 323 (83.2\%) of mothers gave birth vaginally (Table 2 ).

\section{Health Facility-Related Characteristics}

Approximately 108 (27.84\%) mothers were provided with kangaroo mother care at birth for their neonates. Only 39 (10.1\%) mothers had a history of NICU admission with their neonates in recent birth and 301 (77.58\%) mothers were had postnatal care follow-ups during the last births. The majority 342 (88.1\%) mothers had ANC follow-ups during recent pregnancy, out of which 173 (44.50) had above four ANC visits. The majority of mothers 277 (71.39\%) were initiated breastfeeding within one hour after birth and about 378 (97.4\%) were in exclusively breastfeeding (Table 3).

\section{Timing of a Newborn Bath}

With regard to early bathing practice, approximately 125 (32.5\%) with (95\% CI: 27.98-37.32) were practicing early newborn bathing (before 24 hrs of delivery), while 263 (67.8\%) mothers bathed their newborn babies after 24 hours of delivery (late baby bathing).

\section{Women's Knowledge About Newborn Bathing Techniques and Hypothermia}

The majority 366 (94.3\%) mothers used warm water for the first bath of their baby and $269(69.30 \%)$ mothers used Immersion (tub) bathing techniques. Additionally approximately $50.3 \%$ of women had no knowledge on hypothermia while only $44.3 \%$ of mothers had good knowledge about neonatal danger signs (Table 4 ). 
Table I Socio-Demographic Characteristics of Postpartum Mothers at Jimma Town Public Hospitals, Oromia Region, Southwest Ethiopia, 2021

\begin{tabular}{|c|c|c|c|c|c|}
\hline Variables & Categories & $\begin{array}{c}\text { Total } \mathbf{N}(\%) \\
\mathbf{N}=388\end{array}$ & $\begin{array}{l}\text { Late Bathing N (\%) } \\
\qquad \mathbf{N}=\mathbf{2 6 2}\end{array}$ & $\begin{array}{l}\text { Early Bathing } N(\%) \\
\qquad N=\mid 26\end{array}$ & P-value \\
\hline \multirow[t]{2}{*}{ Sex of neonate } & Female & $209(53.9)$ & I $46(69.86)$ & $63(30.14)$ & \multirow[t]{2}{*}{0.289} \\
\hline & Male & $179(46.1)$ & $116(64.80)$ & $63(35.20)$ & \\
\hline \multirow{3}{*}{$\begin{array}{l}\text { Maternal age in } \\
\text { years }\end{array}$} & $<20$ years & $21(5.4)$ & $14(66.67)$ & $7(33.33)$ & \multirow[t]{3}{*}{0.104} \\
\hline & 20-34 years & $335(86.3)$ & $221(65.97)$ & $114(34.03)$ & \\
\hline & $>34$ years & $32(8.2)$ & $27(84.38)$ & $5(15.63)$ & \\
\hline \multirow[t]{5}{*}{ Ethnicity } & Oromo & $293(75.5)$ & $205(69.97)$ & $88(30.03)$ & \multirow[t]{5}{*}{-} \\
\hline & Amhara & $52(13.4)$ & $28(53.85)$ & $24(46.15)$ & \\
\hline & Tigre & $20(5.2)$ & $14(70.00)$ & $6(30.00)$ & \\
\hline & Gurage & I4(3.6) & II (78.57) & $3(2 I .43)$ & \\
\hline & Others & $9(2.3)$ & $4(44.44)$ & $5(55.56)$ & \\
\hline \multirow[t]{4}{*}{ Religion } & Orthodox & $|2|(3 \mid .2)$ & $78(64.46)$ & $43(35.54)$ & \\
\hline & Muslim & $185(47.7)$ & $|3|(70.8 \mid)$ & $54(29.19)$ & \\
\hline & Protestant & $80(20.6)$ & $51(63.75)$ & $29(36.25)$ & \\
\hline & Others & $2(0.5)$ & $2(100.00)$ & - & \\
\hline \multirow[t]{4}{*}{ Marital status } & Married & $366(94.3)$ & $244(66.67)$ & $122(33.33)$ & \\
\hline & Divorced & $12(3.1)$ & $10(83.33)$ & $2(16.67)$ & \\
\hline & Single & $8(2.1)$ & $6(75.0)$ & $2(25.00)$ & \\
\hline & Widowed & $2(0.5)$ & $2(100.0)$ & - & \\
\hline \multirow{6}{*}{$\begin{array}{l}\text { Maternal } \\
\text { educational status }\end{array}$} & Illiterate & $40(10.3)$ & $32(80.0)$ & $8(20.00)$ & \multirow[t]{6}{*}{0.006} \\
\hline & Read and write & $46(11.9)$ & 35 (76.09) & II(23.9I) & \\
\hline & Primary school completed & $94(24.2)$ & 73(77.70) & $21(22.30)$ & \\
\hline & High school completed & $76(19.6)$ & $44(57.9)$ & $32(42.10)$ & \\
\hline & Higher diploma & $56(14.4)$ & $34(60.7)$ & $22(39.3)$ & \\
\hline & Degree/masters & $76(19.6)$ & $44(57.9)$ & $32(42.1)$ & \\
\hline \multirow[t]{2}{*}{ Maternal residency } & Urban & $374(96.4)$ & $25 I(67.1 I)$ & $123(32.89)$ & \\
\hline & Rural & $14(3.6)$ & II (78.57) & $3(21.43)$ & \\
\hline \multirow{2}{*}{$\begin{array}{l}\text { Maternal } \\
\text { occupation }\end{array}$} & Government employment & II $2(28.87)$ & $68(60.71)$ & $44(39.29)$ & \multirow[t]{2}{*}{0.608} \\
\hline & Self-employed & $276(71.13)$ & 194(70.29) & $82(29.7 I)$ & \\
\hline
\end{tabular}

\section{Factors Associated with Early Newborn Bathing}

In this study vaginal mode of delivery were, poor knowledge about danger signs, lack of knowledge about hypothermia and educational level of primary school completed were variables significantly associated with early newborn bathing with p-value less than 0.05 . Mothers who gave birth through the vaginal mode of delivery were had 3.8 times higher odds of early newborn bathing (AOR: 3.84 (95\% CI: 1.96-7.52). Mothers who had poor knowledge about danger signs were had 6.7 times higher odds 
Table 2 Maternal and Obstetric Related Characteristics of Mothers at Jimma Town Public Hospitals, Oromia Region, Southwest Ethiopia, 2021

\begin{tabular}{|c|c|c|c|c|c|}
\hline Variables & Categories & $\begin{array}{l}\text { Total N (\%) } \\
\mathbf{N = 3 8 8}\end{array}$ & $\begin{array}{l}\text { Late Bathing } N(\%) \\
\qquad N=262\end{array}$ & $\begin{array}{l}\text { Early Bathing } N(\%) \\
\qquad N=126\end{array}$ & p-value \\
\hline \multirow[t]{2}{*}{ Gravidity } & 1 & $149(38.4)$ & $99(66.44)$ & $50(33.56)$ & \\
\hline & $\geq 2$ & $239(61.6)$ & $163(68.20)$ & $76(31.80)$ & \\
\hline \multirow[t]{2}{*}{ Parity } & 1 & $177(45.62)$ & $118(66.67)$ & $59(33.33)$ & \multirow[t]{2}{*}{0.017} \\
\hline & $\geq 2$ & $211(54.38)$ & $144(68.25)$ & $67(31.75)$ & \\
\hline \multirow[t]{2}{*}{ Place of delivery } & Home delivery & $14(3.60)$ & II(78.57) & $3(21.43)$ & \\
\hline & Health facility & $374(96.4)$ & $25 I(67 . I I)$ & $123(32.8)$ & \\
\hline \multirow[t]{2}{*}{ Type of pregnancy } & Single & $367(94.59)$ & $252(68.66)$ & $115(31.34)$ & \multirow[t]{2}{*}{0.045} \\
\hline & Multiple & $2 I(5.4 I)$ & $10(47.62)$ & II (52.38) & \\
\hline \multirow[t]{2}{*}{ Preparedness for delivery } & Yes & 329 (84.79) & $218(66.26)$ & III(33.74) & \multirow[t]{2}{*}{0.209} \\
\hline & No & $59(15.21)$ & $44(74.58)$ & $15(25.42)$ & \\
\hline \multirow{2}{*}{$\begin{array}{l}\text { Complications during recent } \\
\text { pregnancy }\end{array}$} & No & $348(89.7)$ & $242(69.54)$ & $106(30.46)$ & \multirow[t]{2}{*}{0.012} \\
\hline & Yes & $40(10.3)$ & $20(50.00)$ & $20(50.00)$ & \\
\hline \multirow{2}{*}{$\begin{array}{l}\text { Previous chronic medical } \\
\text { problem }\end{array}$} & No & $375(96.6)$ & $254(67.73)$ & $121(32.27)$ & \multirow[t]{2}{*}{0.639} \\
\hline & Yes & $13(3.4)$ & $8(61.54)$ & $5(38.46)$ & \\
\hline \multirow[t]{2}{*}{ Presentation } & Cephalic & $374(96.4)$ & $254(67.91)$ & $120(32.09)$ & \multirow[t]{2}{*}{0.398} \\
\hline & Non-cephalic & $4(3.6)$ & $8(57.14)$ & $6(42.86)$ & \\
\hline \multirow[t]{2}{*}{ Mode of delivery } & Vaginal & $323(83.2)$ & $238(73.68)$ & $85(26.32)$ & \multirow[t]{2}{*}{0.00} \\
\hline & Cesarean section & $65(16.8)$ & $24(36.92)$ & $4 I(63.08)$ & \\
\hline
\end{tabular}

of early newborn bath practice (AOR: 6.78 (95\% CI: 3.77-12.19). The odds of early newborn bathing practice were $65 \%$ less likely among mothers who had knowledge about hypothermia than their counterparts (AOR: 0.35 (95\% CI: $0.20-0.58$ ). Similarly, mothers whose educational level until primary school completed were $67 \%$ less likely to practice early newborn bathing than their counterpart (AOR: 0.33 (95\% CI: 0.15-0.73) (Table 5).

\section{Discussion}

The purpose of this study was to assess early newborn bathing practices and associated factors in Jimma town. In this study, it was found that about (32.5\%), mothers were practicing early newborn bathing. This result is in line with study conducted in Lebanon and Harer, Ethiopia which reported $33.3 \%{ }^{13}$ and $35.4 \%{ }^{18}$ respectively. This result is higher than the study conducted in Nigeria where the prevalence was $22 \cdot 8 \% .{ }^{19}$ The possible reason for the difference might be due to the variations in study design, since a study in Nigeria was conducted from direct observations to report on neonatal care practices up to 2 hours after birth but our study was based on the memory and recall ability of the mother, which may overestimate findings. Additionally a study in Nigeria was conducted in community level but our study was institutional based which may overestimate the result since the study population included only women who came for newborn immunization.

In the current study, mothers who gave birth through the vaginal mode of delivery were more likely to practice early neonatal baths than those who gave birth by cesarean section. This finding is similar to that of a study conducted in Nepal. ${ }^{20}$ This may be because women who delivered through vaginal mode may have been discharged earlier from the 
Table 3 Health Facility Characteristics of Mothers at Jimma Town Public Hospitals, Oromia Region, Southwest Ethiopia, 202I

\begin{tabular}{|c|c|c|c|c|c|}
\hline Variables & Categories & $\begin{array}{l}\text { Total } \mathbf{N}(\%) \\
\mathbf{N}=388\end{array}$ & $\begin{array}{l}\text { Late Bathing } N(\%) \\
\qquad N=262\end{array}$ & $\begin{array}{l}\text { Early Bathing N (\%) } \\
\qquad N=\mid 26\end{array}$ & p-value \\
\hline \multirow[t]{2}{*}{ NICU admission history } & Yes & $39(10.1)$ & $16(41.03)$ & $23(58.97)$ & \multirow[t]{2}{*}{0.00} \\
\hline & No & $349(89.9)$ & $246(70.49)$ & $103(29.51)$ & \\
\hline \multirow[t]{2}{*}{ KMC } & Yes & $108(27.84)$ & $71(65.74)$ & $37(34.26)$ & \multirow[t]{2}{*}{$0.64 I$} \\
\hline & No & $280(72.16)$ & $191(68.21)$ & $89(31.79)$ & \\
\hline \multirow{2}{*}{$\begin{array}{l}\text { Postnatal care follow up during } \\
\text { last birth }\end{array}$} & Yes & $30 \mathrm{I}(77.58)$ & $202(67.1)$ & $99(32.9)$ & \multirow[t]{2}{*}{0.745} \\
\hline & No & $87(22.42)$ & $60(69.0)$ & $60(69.00)$ & \\
\hline \multirow[t]{2}{*}{ ANC during last pregnancy } & Yes & $342(88.10)$ & $224(65.5)$ & II $8(34.5)$ & \multirow[t]{2}{*}{0.20} \\
\hline & No & $46(11.90)$ & $38(82.61)$ & $8(17.39)$ & \\
\hline \multirow[t]{2}{*}{ Number of visits } & $\leq 4$ & $169(43.50)$ & $12 \mid(7 \mid .6)$ & $48(28.40)$ & \multirow[t]{2}{*}{0.019} \\
\hline & $>4$ & $173(44.50)$ & $103(59.5)$ & $70(40.50)$ & \\
\hline \multirow[t]{2}{*}{ Early breastfeeding initiation } & Yes & 277 (7I.39) & $196(70.76)$ & $81(29.24)$ & \multirow[t]{2}{*}{0.32} \\
\hline & No & III (28.6I) & $66(59.46)$ & $45(40.54)$ & \\
\hline
\end{tabular}

Table 4 Overall Knowledge of Mothers and Technique of Newborn Bathing at Jimma Town Public Hospitals, Oromia Region, Southwest Ethiopia, 2021

\begin{tabular}{|c|c|c|c|c|c|}
\hline \multirow[t]{2}{*}{ Variables } & \multirow[t]{2}{*}{ Categories } & \multirow{2}{*}{$\begin{array}{l}\text { Total N (\%) } \\
\mathbf{N}=388\end{array}$} & \multicolumn{2}{|c|}{ Bathing Practice } & \multirow[t]{2}{*}{ p-value } \\
\hline & & & $\begin{array}{l}\text { Late Bathing } \\
N \text { (\%) } \mathbf{N}=\mathbf{2 6 2}\end{array}$ & $\begin{array}{l}\text { Early Bathing } \\
N(\%) \quad N=\mid 26\end{array}$ & \\
\hline \multirow{2}{*}{$\begin{array}{l}\text { Type of water used for } \\
\text { newborn bathing }\end{array}$} & Warm water & $366(94.3)$ & $250(68.3)$ & $116(31.7)$ & \multirow[t]{2}{*}{0.181} \\
\hline & Coldwater & $22(5.7)$ & $12(54.5)$ & $10(45.5)$ & \\
\hline \multirow[t]{3}{*}{ Bathing techniques } & Immersion (tub) bathing & $269(69.3)$ & $176(65.4)$ & $93(34.6)$ & \multirow[t]{3}{*}{0.28} \\
\hline & Swaddled (tub) bathing & $55(14.2)$ & $42(76.4)$ & $13(23.6)$ & \\
\hline & Sponge bathing (wiper) & $64(16.5)$ & $44(68.8)$ & $20(3 \mid .2)$ & \\
\hline \multirow[t]{2}{*}{ Knowledge about hypothermia } & Yes & 193(49.7) & $152(78.8)$ & $4 \mid(2 \mid .2)$ & \multirow[t]{2}{*}{0.00} \\
\hline & No & $195(50.3)$ & $110(56.4)$ & $85(43.6)$ & \\
\hline \multirow{2}{*}{$\begin{array}{l}\text { Mean knowledge about } \\
\text { neonatal danger sign }\end{array}$} & Good knowledge & $172(44.3)$ & $|5|(87.8)$ & $2 I(I 2.2)$ & \multirow[t]{2}{*}{0.00} \\
\hline & Poor knowledge & $216(55.7)$ & III(5I.4) & $105(48.6)$ & \\
\hline
\end{tabular}

hospital and may practice early bathing than mothers delivered through $\mathrm{c} / \mathrm{s}$ whom stay longer in hospital since health professionals can educate and follow early bath in the hospital.

In this study, the mothers with primary school completed educational level had a higher risk of practiced early neonatal bathing than with mothers with Degree/masters educational level, which is supported by studies conducted in Eastern Ethiopia. ${ }^{18}$ This may be due to the reason that women with higher educational status may have information from their working area and may understand and practice what health care professionals told to them to do or not to do something about their newborn. 
Table 5 Factors Associated with Early Neonatal Bathing Practice Among the Mothers at Jimma Town Public Hospitals, Oromia Region, Southwest Ethiopia, 202I

\begin{tabular}{|c|c|c|c|c|c|c|}
\hline \multirow[t]{2}{*}{ Variables } & \multirow[t]{2}{*}{ Category } & \multicolumn{2}{|c|}{ Timing of Newborn Bath } & \multirow[t]{2}{*}{ COR $(95 \% \mathrm{Cl})$} & \multirow[t]{2}{*}{ AOR (95\% Cl) } & \multirow[t]{2}{*}{ p-value } \\
\hline & & $\begin{array}{c}\text { Late } \\
\text { Newborn } \\
\text { Bath }\end{array}$ & $\begin{array}{c}\text { Early } \\
\text { Newborn } \\
\text { Bath }\end{array}$ & & & \\
\hline \multirow{2}{*}{$\begin{array}{l}\text { ANC during last } \\
\text { pregnancy }\end{array}$} & Yes & $224(65.50)$ & $118(34.50)$ & I & I & \\
\hline & No & $38(82.61)$ & $8(17.39)$ & $0.40(0.18-0.88)$ & $0.82(0.31-2.19)$ & 0.690 \\
\hline \multirow[t]{2}{*}{ Mode of delivery } & Cs & $24(36.92)$ & $4 I(63.08)$ & 1 & I & \\
\hline & Vaginal & $238(73.68)$ & $85(26.32)$ & $0.21(0.12-0.37)$ & $3.84(1.96-7.52)$ & $0.000 *$ \\
\hline \multirow{2}{*}{$\begin{array}{l}\text { Early breastfeeding } \\
\text { initiation }\end{array}$} & Yes & $196(70.76$ & $8 I(29.24$ & 1 & 1 & \\
\hline & No & $66(59.46$ & $45(40.54$ & $1.65(1.04-2.61)$ & $1.38(0.79-2.43)$ & 0.263 \\
\hline \multirow{2}{*}{$\begin{array}{l}\mathrm{NICU} \text { admission } \\
\text { history }\end{array}$} & Yes & $16(41.03$ & $23(58.97)$ & I & I & \\
\hline & No & $246(70.49)$ & $103(29.5 \mathrm{I})$ & $0.29(0.15-0.57)$ & $0.52(0.22-1.26)$ & 0.148 \\
\hline \multirow{2}{*}{$\begin{array}{l}\text { Knowledge about } \\
\text { danger sign }\end{array}$} & Good & $|5|(87.8)$ & $2 I(12.2)$ & 1 & I & \\
\hline & Poor & $|I|(5 I .4)$ & $105(48.6)$ & $0.15(0.09-0.25)$ & $6.78(3.77-12.19)$ & $0.000 *$ \\
\hline \multirow[t]{3}{*}{ Maternal age in years } & $<20$ years & 14(66.67) & $7(33.33)$ & $2.7(0.72-10.07)$ & $3.28(0.7 I-15.27)$ & 0.130 \\
\hline & 20-34 years & $221(65.97)$ & $114(34.03)$ & $2.79(1.05-7.43)$ & $1.94(0.62-6.03)$ & 0.252 \\
\hline & $>34$ years & $27(84.38)$ & $5(15.63)$ & & & \\
\hline \multirow{2}{*}{$\begin{array}{l}\text { Knowledge about } \\
\text { hypothermia }\end{array}$} & No & $152(78.8)$ & $4 I(2 \mid .2)$ & I & I & \\
\hline & Yes & $110(56.4)$ & $85(43.6)$ & $2.87(1.83-4.48)$ & $0.35(0.20-0.58)$ & $0.000 *$ \\
\hline \multirow[t]{6}{*}{ Educational level } & Illiterate & $32(80.00)$ & $8(20.00)$ & $0.34(-0.14-0.84)$ & $0.425(0.14-1.29)$ & 0.132 \\
\hline & Read and write & $35(76.09)$ & II (23.9I) & $0.43(0.19-0.98)$ & $0.39(0.15-1.01)$ & 0.052 \\
\hline & Primary school completed & 73(77.7) & $2 \mathrm{I}(22.3)$ & $0.40(0.203-0.770)$ & $0.33(0.15-0.73)$ & $0.006 *$ \\
\hline & High school completed & $44(57.9)$ & $32(42.10)$ & $1.00(0.53-1.90)$ & $0.92(0.42-1.99)$ & 0.827 \\
\hline & Higher diploma & $34(60.7)$ & $22(39.3)$ & $0.89(0.44-1.78)$ & $0.79(0.34-1.82)$ & 0.579 \\
\hline & Degree and Masters & $44(57.9)$ & $32(42.1)$ & I & 1 & \\
\hline
\end{tabular}

Notes: *Significant at $\mathrm{p}$-value $<0.05$ in multivariable analysis, $\mathrm{I}=$ considered as reference category.

Moreover, this study revealed that mothers who had poor knowledge about newborn danger signs were practiced early bathing. This finding was in line with other studies conducted in eastern Tigray. ${ }^{17}$ This may be due to that most mothers who did not know dangerous signs including hypothermia can practice early bathing. In addition, this study revealed that mothers who did not know hypothermia practice early newborn bathing. This may be because mothers with no idea about hypothermia and related complications can practice early bathing of the newborn more than their counterparts. The limitations of this study were using a cross sectional study design that does not show a cause-effect relationship. This study captured data based on the memory and recall ability of the mother that may over or underestimated the result. Another limitation is being facility based which affect the magnitude of newborn bath practice among postnatal mothers in the community. 


\section{Conclusion and Recommendation}

In this study, 126 (32.5\%) of the study participants had early newborn bathing practices which is higher and more effort is needed to promote late newborn bath practices both in health facilities and at home. The factors that were significantly associated with the early neonatal bathing practice were the mode of delivery, lower educational status, poor knowledge about danger signs, and mothers not knowing about hypothermia. In Ethiopia, majority of deliveries are usually discharged home before 24 hours of delivery, this implies that post-partum mothers may not have adequate understanding of the actual number of hours to delay newborn bathing. Using maternal education as a key strategy helps in the continuity of newborn care from hospital to home. ${ }^{21}$ Therefore, health care professionals should use ANC and immediately after delivery/postnatal period as the right time for educating pregnant and delivered women about time of bathing their newborns. Further large community based studies should be conducted using other data collection methods including newborn care narratives, observations of bathing and in-depth interviews with mothers, grandmothers and fathers to determine the real time of newborn bath, which is representative.

\section{Abbreviations}

AHR, adjusted hazard ratio; ANC, antenatal care; FMoH, Federal Minister of Health; GA, gestational age; HBV, hepatitis type B virus; HEW, health extension worker; HIV, human immune-deficiency virus; IMR, infant mortality rate; JMC, Jimma Medical Center; NICU, neonatal intensive care unit; NMR, newborn mortality rate; PNC, postnatal care; SGH, Shanan Gibe Hospital; SVD, spontaneous vaginal delivery; TBA, traditional birth attendant; WHO, World Health Organization.

\section{Data Sharing Statement}

The raw data file could be provided for research purposes only, upon request via e-mail of the corresponding author.

\section{Ethical Consideration}

Before data collection, official letter was obtained from the Jimma University review board and official permission was asked from Jimma medical center. The participants were informed about the purpose of the study and were asked their permission before data collection. In addition, the confidentiality of the information was assured and the privacy of the study participants was respected to ensure confidentiality the names of respondents were not written on the consent form. Generally, all methods in the study were carried out in accordance with the declaration of Helsinki as a statement of ethical principles for medical research involving human subjects.

\section{Acknowledgments}

First, we would like to thank Jimma University Institute of Health, Faculty of Health Science, and School of Midwifery for allowing us to do this research paper. Secondly, we would like to thank Jimma Medical Center and Shanan Gibe Hospital administrators for their absolute willingness to help. It is also our pleasure to thank the data collectors, supervisors, and participants for their cooperation.

\section{Author Contributions}

All authors made a significant contribution to the work reported: whether that is in the conception, study design, execution, acquisition of data, analysis, interpretation and all these areas: took part in drafting, revising or critically reviewing the article; gave final approval of the version to be published; have agreed on the journal to which the article has been submitted; and agree to be accountable for all aspects of the work.

\section{Funding}

The authors declare that no financial funding was received for the study, authorship, and publication of this article. 


\section{Disclosure}

The authors declare no conflicts of interest in this work.

\section{References}

1. New K. Evidence-based guidelines for infant bathing; 2019:1-4.

2. Adejuyigbe EA, Bee MH, Amare Y, et al. "Why not bathe the baby today? ": A qualitative study of thermal care beliefs and practices in four African sites. BMC Pediatr. 2015;15:1-7. doi:10.1186/s12887-015-0470-0

3. World Health Organization. Recommendations on postnatal care of the mother and the newborn; 2013.

4. Neonatal care. Directorate, obstetrics and gynaecology guideline CPNMHS 2021. North Metropolitan Health Service; 2021.

5. Colwell A. To bathe or not to bathe: the neonatal question. $J$ Neonatal Nurs. 2015;34(4):216-219. doi:10.1891/0730-0832.34.4.216

6. Morton C, Ramos RR, Ehrgott A, Quental MM, Burridge A, Rutledge DN. Does changing newborn bath procedure alter newborn temperatures and exclusive breastfeeding? Neonatal Network. 2018;37(1):4-10. doi:10.1891/0730-0832.37.1.4

7. Behring A, Vezeau T, Fink R. Timing of the newborn first bath. Neonatal Network. 2018. doi:10.1891/0730-0832.22.1.39

8. Madhu R, Chandran V, Anandan V, et al. Indian academy of pediatrics guidelines for pediatric skin care. Indian Pediatr. 2021;58(2):153-161. doi:10.1007/s13312-021-2133-6

9. Gözen D, Çaka SY, Beşirik SA, Perk Y. First bathing time of newborn infants after birth: a comparative analysis. J Spec Pediatr Nurs. 2019;24(2): e12239. doi:10.1111/jspn.12239

10. Chamberlain J, Mccarty S, Sorce J, et al. Impact on delayed newborn bathing on exclusive breastfeeding rates, glucose and temperature stability, and weight loss. J Neonatal Nurs. 2019;25(2):74-77. doi:10.1016/j.jnn.2018.11.001

11. Mullany LC. Neonatal hypothermia in low-resource settings. YSPER. 2015;34(6):426-433. doi:10.1053/j.semperi.2010.09.007

12. Latha S, Kamala S, Srikanth S. Newborn care practices in a tribal community in tamilnadu: a qualitative study. Int J Contemp Pediatr. 2017;4 (3):869-874. doi:10.18203/2349-3291.ijcp20171688

13. Mardini J, Rahme C, Matar O, et al. Newborn's first bath: any preferred timing? A pilot study from Lebanon. BMC Res Notes. 2020;13(1):1-6. doi:10.1186/s13104-020-05282-0

14. Ukke G G, Diriba K, Diriba K. Prevalence and factors associated with neonatal hypothermia on admission to neonatal intensive care units in Southwest Ethiopia - a cross-sectional study. PLoS One. 2019;14(6)1-13.

15. Majumder S, Najnin Z. Knowledge and attitude of essential newborn care among postnatal mothers in Bangladesh. J Health Res. 2018;32 (6):440-448. doi:10.1108/JHR-05-2018-0015

16. Self Learning Module. Newborn Thermoregulation; 2013.

17. Misgna HG, Gebru HB, Birhanu MM. Knowledge, practice and associated factors of essential newborn care at home among mothers in Gulomekada District, Eastern. BMC Pregnancy Childbirth. 2016;16:1-8. doi:10.1186/s12884-016-0931-y

18. Welay FT, Mengesha MB, Gebremedhin TS. Early newborn bath and associated factors among parturient women who gave birth in the last month in Harar Region, Eastern Ethiopia, 2017. Abstract. 2020;196-202. doi:10.2174/1874944502013010196

19. Ayenew A, Abebe M, Ewnetu M. Essential newborn care and associated factors among obstetrical care providers in awi zone health facilities, Northwest Ethiopia: an institutional-based cross-sectional study. Pediatric Health Med Ther. 2020;11:449-458. doi:10.2147/PHMT.S276698

20. Acharya SR, Poudel S. Factors associated with maternal and neonatal health care practices: a study from Nepal. Int $J$ Child Health Nutr. 2020;10:186-192.

21. Subramanian L, Murthy S, Bogam P, et al. Just in time postnatal education programmes to improve newborn care practices: needs and opportunities in low resource settings. BMJ Global Health. 2020:1-7. doi:10.1136/bmjgh-2020-002660

Pediatric Health, Medicine and Therapeutics

\section{Dovepress}

\section{Publish your work in this journal}

Pediatric Health, Medicine and Therapeutics is an international, peer-reviewed, open access journal publishing original research, reports, editorials, reviews and commentaries. All aspects of health maintenance, preventative measures and disease treatment interventions are addressed within the journal. Practitioners from all disciplines are invited to submit their work as well as healthcare researchers and patient support groups. The manuscript management system is completely online and includes a very quick and fair peer-review system. Visit http://www.dovepress.com/ testimonials.php to read real quotes from published authors.

Submit your manuscript here: http://www.dovepress.com/pediatric-health-medicine-and-therapeutics-journal 